\title{
Analysis of Land Use, Land-use Change, and Forestry (LULUCF) and Construction of Statistics in Korea
}

\author{
Seon Cheol Yu, ${ }^{1}$ Dong Bin Shin, ${ }^{2}$ and Jong Wook Ahn ${ }^{2^{*}}$ \\ ${ }^{1}$ Smart Urban Space Institute, Anyang University \\ 22, Smadeok-ro 37 Beon-gil, Manan-gu, Anayang-si, Gyeonggi-do 14028, Korea \\ ${ }^{2}$ Dept. of Urban Information Engineering, Anyang University, \\ 22, Smadeok-ro 37beon-gil, Manan-gu, Anayang-si, Gyeonggi-do 14028, Korea
}

(Received February 21, 2019; accepted April 30, 2019)

Keywords: LULUCF, remote sensing, statistics, Korea

In this study, we analyze land use, land-use change, and forestry (LULUCF) in Korea, referring to the Intergovernmental Panel on Climate Change (IPCC) Good Practice Guidance (GPG) (2003), and propose a method for the systematic construction of statistics for LULUCF. Land-use changes across six categories, including settlement, forest, cropland, grassland, wetland, and other land types, were analyzed using digital topographic, land cover, and land zone maps from the Korea Land Information System (KLIS) using Landsat TM satellite images as primary data. The results of this study indicate that a classification system for each LULUCF category should be established to improve the statistical accuracy of this data and spatial big data applications for land-use analysis should be developed. Furthermore, a method is proposed for the systematic construction of statistics for LULUCF to determine the Korean national greenhouse gas inventory. An explanation of the recommended approach, including gathering satellite image data, LULUCF classifications, and establishing land-use change statistics, is presented. To fulfill the emission reduction targets set in the Paris Agreement, these greenhouse gas emission statistics are essential for different sectors to establish the diverse policies and action plans required to be effective. This will make the national-level monitoring of LULUCF more efficient, leading to a significant reduction in greenhouse gas emission.

\section{Introduction}

At the 21st Council of Parties (COP21) of the United Nations Framework Convention on Climate Change (UNFCCC) held in December 2015, in Paris, France, the Paris Agreement on a future climate protocol beyond 2020 was adopted. Unlike the 1997 Kyoto Protocol that obliged advanced countries to reduce emissions, the Paris Agreement is a universal climate agreement that is binding for all 195 state parties. It includes planned contribution to emission reduction for each state party and a method of conducting regular and comprehensive monitoring and reporting of targets. In Korea, from the 2014 statistics, the total amount of greenhouse gas

*Corresponding author: e-mail: ajw0603@anyang.ac.kr https://doi.org/10.18494/SAM.2019.2340 
emissions for 2017 was predicted to be 690.5 million tons of $\mathrm{CO}_{2}$ eq, which is the 12th largest emission volume in the world, ${ }^{(1,2)}$ and among OECD member countries, the sixth largest volume of greenhouse gases, behind the United States, Japan, Germany, Canada, and Mexico. That led Korea to develop and implement a diverse range of policies to reduce emission. In 2011, recommended targets for developing countries ranged between 15 and 30\% reductions from business as usual (BAU). Korea set a voluntary emission reduction target at the highest level, deciding to implement a $30 \%$ emission reduction from BAU by 2020 . Following this, the Korean government enacted the Low Carbon Green Growth Act to establish a comprehensive greenhouse gas management regulation in 2010 and began the systematic construction of statistics for about five different greenhouse gas inventories, for energy, industrial processing, agriculture and livestock breeding, land use, land-use change, and forestry (LULUCF), and waste. However in Korea, as of 2017, the systematic construction of statistics for the LULUCF sector was still insufficient according to the Intergovernmental Panel on Climate Change (IPCC) (GPG 2003: Good Practice Guidance 2003). The total land area and the land-use categories that had changed were not distinguishable. Furthermore, no statistics on land-use conversions existed. The absorption volume of greenhouse gases in Korea's LULUCF sector accounted for $6.1 \%$ of total emission and for this absorption volume to be recognized globally, statistics for the accurate monitoring and data collection of land-use change categories for the past two decades must be constructed. ${ }^{(3)}$ Therefore, in this study, we intend to analyze LULUCF in Korea by referring to global standards in accordance with the IPCC GPG 2003 and propose a method for the systematic construction of these statistics for the LULUCF sector.

To analyze land-use changes in Korea and propose a method of systematic construction of sector inventories, this study was conducted by reviewing the theoretical background and preceding studies of analyzing the case of LULUCF in Korea, and suggesting a new method for constructing LULUCF statistics. In the review, the current status of the national system for calculating greenhouse gas inventories and constructing statistics in Korea was examined. Then, the differentiation of the study was presented by reviewing the implementation of relevant studies from both within and outside Korea. In the case of LULUCF, satellite image data, digital topographic maps, land cover maps, and Korea Land Information System (KLIS) land-use zoning maps were used to develop a methodology for assessing land-use changes nationwide in Korea over a 20-year period (1987-2007). Finally, on the basis of the results of the review on the theoretical background and preceding studies as well as the results of the case analysis, a basic approach for establishing a national greenhouse gas inventory for the LULUCF sector was proposed. This included a method of extracting spatial data using remote sensing and a method for constructing land-use change statistics.

\section{Review on Theoretical Background and Preceding Studies}

\subsection{National greenhouse gas inventory system}

The IPCC is an intergovernmental climate change consultative body consisting of 3000 environment experts from different countries, established by the World Meteorological 
Organization (WMO) and United Nations Environment Program (UNEP) to deal with global environmental issues related to climate. The IPCC suggests guidelines and specifies standards for estimating global greenhouse gas emissions. Countries, including the United States, Japan, Australia, and European countries, apply IPCC guidelines to estimate their greenhouse gas emissions. The IPCC has developed Guidelines for National Greenhouse Gas Inventories (1996, 2006) and the GPGs (2003) to provide an internationally agreed methodology for calculating national greenhouse gas inventories to be reported to the UNFCCC (Table 1).

The 1996 IPCC guidelines specify the scope of establishing a national inventory. At COP9 hosted in 2003 in Italy, the IPCC GPG 2003 for the LULUCF sector was adopted, and a decision was made to follow these guidelines from 2005 to write national greenhouse gas inventory reports (Annual National Greenhouse Gas Inventory, NIR). Then, at COP10 hosted in Argentina in 2004, a recommendation for Annex I parties was made to write greenhouse gas inventories about the activities specified in the Kyoto Protocol Articles 3.3 and 3.4 regarding greenhouse gas sinks based on the GPG 2003 from 2007. Furthermore, in 2006, the IPCC developed guidelines for writing national greenhouse gas inventory reports and obliged state parties to submit reports based on the guidelines, in the categories of energy; industrial processes and product use; agricultural land, forest, and other land categories; and waste. ${ }^{(4-7)}$

Looking at the GPG 2003 in detail, of the different sectors referred to above, the forestry and other types of land-use (LULUCF) sector are classified into further six categories including forest, cropland, grassland, wetland, settlement, and other land types. In these guidelines, land use is recommended to be classified by applying three classification approaches from Tier 1 to 3 in accordance with the content of the data. Tier 1 data specifies the total area of each land category but does not offer any detailed information about the area of land and how it has changed over time. Tier 2 data can explain the changing land-use category trends for the area of land. Tier 3 data can provide supporting information related to changes in land-use categories on a spatial basis. The consideration for the selection of an appropriate classification approach for the land-use category includes (1) spatial data needed for reporting to meet Kyoto Protocol obligation, (2) nationwide-scale data, and (3) availability of appropriate time-series data. ${ }^{(6)}$

Table 1

Changes in IPCC Guideline.

\begin{tabular}{|c|c|c|c|}
\hline Division & $1996 \mathrm{GL}$ & GPG 2000, GPG 2003 & $2006 \mathrm{GL}$ \\
\hline Content & $\begin{array}{l}\text { - LUCF } \\
\text { - Agriculture }\end{array}$ & $\begin{array}{l}\text { - LULUCF (GPG 2003) } \\
\text { - Agriculture (GPG 2000) }\end{array}$ & - AFOLU \\
\hline Major changes & & $\begin{array}{l}\text { - Including all land uses and land-use } \\
\text { changes } \\
\text { - Forest, cropland, grassland, wetland, } \\
\text { settlement, other land types } \\
\text { - Including all carbon pool } \\
\text { - Biomass, litter layer, dead tree, soil } \\
\text { - Improvement of methodology, coefficient }\end{array}$ & $\begin{array}{l}\text { - Integration of land-related } \\
\text { activities } \\
\text { - Agriculture, forest, other } \\
\text { land uses }\end{array}$ \\
\hline $\begin{array}{l}\text { Application of } \\
\text { the convention }\end{array}$ & $\begin{array}{l}\text { - Developing countries } \\
\text { (obligatory use) } \\
\text { - GHG statistics by } \\
\text { UNFCCC }\end{array}$ & $\begin{array}{l}\text { - Advanced countries (obligatory use) } \\
\text { - GHG statistics by UNFCCC } \\
\text { - Developing countries (recommended use) }\end{array}$ & $\begin{array}{l}\text { - Developing and advanced } \\
\text { countries (voluntary use) }\end{array}$ \\
\hline
\end{tabular}


When the UNFCCC climate change agreement was signed in 1992, Korea was recognized as a Non-Annex I State Party. Thus, no greenhouse gas reduction obligation was placed on Korea for the 1st period between 2008 and 2012. However, Korea had promised to submit greenhouse gas statistics to fulfill the standards applied to advanced countries when joining the OECD. Korea also needed to amass national greenhouse gas statistics in accordance with the IPCC guidelines to respond to the mandatory emission reduction obligations in the Kyoto Protocol. For the calculation, reporting, and verification of Korea's national greenhouse gas statistics in line with the guidelines, Korea's national greenhouse gas inventory is classified into five categories - energy, industrial process, LULUCF, agriculture, and waste-, on the basis of 2006 IPCC guidelines. Korea's inventory is managed by the Greenhouse Gas Inventory and Research Center (GIR). Different agencies are used for each sector to calculate and direct activities designated for the systematic construction of greenhouse gas inventories.

The IPCC GPG 2003 demands the classification of subcategories of the LULUCF sector, as well as the calculation of land area that remains in the same category and the area of land whose category changes over time from other categories. To examine the current status of data construction for each LULUCF category, inventory calculations are carried out only for the forest, agricultural land, grassland, and wetland subcategories as of 2017 (2014 statistics). Furthermore, statistics on the inventory of the area of land whose category was converted from others has yet to be constructed.

As for settlement, the inventory has not yet constructed statistics owing to the lack of data of activities that affect the land. The inventory for other types of land has also not yet been constructed, because the entire land use and converted land areas cannot be precisely calculated yet. Modeled examples that explain different land-use categories are necessary to calculate the accumulated amount of carbon, as well as the greenhouse gas emission and absorption volumes of the cropland, forestry, and land use for other purposes (LULUCF) sectors. ${ }^{(7)}$ That is why Annex I state parties have mandated the systematic construction of statistics based on remote sensing data obtained from satellite images and other diverse references, to accumulate relevant data for this purpose.

Korea's national greenhouse inventory statistics currently submitted to the UNFCCC include LUCF statistics following the 1996 inventory guideline. Therefore, still no detailed LULUCF statistics for Korea exist. As of 2014, the statistics constructed for each category were limited to land that remained in the same category as the previous year, so statistics on changed landuse area categories must also be constructed (Table 2). As for the greenhouse gas inventory in the LULUCF sector, the land area for each of the six categories, as well as information about the area of land that has had a change in category from others, must still be constructed. Also, the consistency of the calculation of the converted land area in each category and the total land area must be maintained on the basis of the background information about the conversion of land-use categories over the previous 20 -year period. Furthermore, to recognize greenhouse sinks at the national level, the area of land undergoing changes in land-use categories during the previous 20 -year period must be tracked. 
Table 2

Volume of greenhouse gas absorption in the LULUCF sector in Korea.

\begin{tabular}{lrrrrrrrr}
\hline Category & 1990 & 2000 & 2010 & 2012 & 2013 & 2014 & $\begin{array}{c}\text { Increase from } \\
\text { the 1990 level }\end{array}$ & $\begin{array}{c}\text { Increase from } \\
\text { the 2013 level }\end{array}$ \\
\hline 5A Forest & -34.6 & -61.8 & -59.4 & -49.3 & -47.2 & -47.0 & $35.8 \%$ & $-0.5 \%$ \\
5B Cropland & 0.7 & 3.3 & 4.9 & 4.4 & 4.4 & 4.4 & $487.6 \%$ & $0.5 \%$ \\
5C Grassland & -0.5 & -0.6 & -0.2 & -0.1 & -0.1 & -0.1 & $-80.8 \%$ & $-11.5 \%$ \\
5D Wetland & 0.3 & 0.3 & 0.3 & 0.3 & 0.3 & 0.3 & $-3.1 \%$ & $-4.1 \%$ \\
\hline Total & -34.1 & -58.8 & -54.3 & -44.7 & -42.8 & -42.5 & $24.5 \%$ & $-0.7 \%$ \\
\hline
\end{tabular}

1 million tons, $\mathrm{CO}_{2}$ eq.

Sources: GIR, 2016, National Greenhouse Gas Inventory Report of Korea.

\subsection{Literature review}

Literature relevant to the construction of the LULUCF inventory from both Korea and other countries was reviewed. First, among foreign literature, Teixeira et al. ${ }^{(8)}$ reported the evaluation of the potential of the clean development mechanism (CDM) business in the LULUCF sector by analyzing the national greenhouse gas energy sector profile in Brazil, a country that has plentiful carbon sinks. ${ }^{(8,9)}$ However, their study was limited only to profile analysis, and they failed to construct a LULUCF matrix for applying the guidelines suggested by the IPCC. In another study, Achard et al. examined the IPCC guidelines in accordance with the necessity of a methodology for analyzing changes in land categories, analyzed the technical application of the guidelines through global case studies, and then proposed a method for developing a LULUCF matrix based on remote sensing with satellite images. ${ }^{(10)}$ However, the analysis of the study was not implemented with actual data, so it remained a theoretical study.

In domestic studies, Choi established a land-use change matrix using case study areas by employing various related national statistics for LULUCF and spatial information including satellite images. ${ }^{(1)}$ Yu et al. tracked the degree of change in the LULUCF sector by using satellite images and spatial information for the Gyeonggi-do region in Korea. ${ }^{(12)}$ However, both those approaches have limitations because the analysis was implemented only in three cities, not at the national level.

Our study is differentiated from other studies because we use nationwide satellite images and diverse spatial information for the construction of a LULUCF matrix for the previous 20 -year period and also propose a methodology for the establishment of national greenhouse gas inventory statistics in the future (Table 3).

\section{LULUCF Case Analysis}

\subsection{Framework of analysis}

Satellite images were used as baseline data and 1/25000-scale digital and zoning maps from KLIS as reference data for analyzing land-use changes in Korea for 20 years. 
Table 3

Preceding studies and differentiation from this study.

\begin{tabular}{|c|c|c|c|}
\hline & tudy by & Major content & Limitations \\
\hline \multirow[b]{2}{*}{ Overseas } & $\begin{array}{l}\text { Teixeira et al. } \\
\text { (2006) }\end{array}$ & $\begin{array}{l}\text { Analyzed the profile of Brazil's national } \\
\text { greenhouse gas energy sector and } \\
\text { accordingly evaluated the potential of the } \\
\text { LULUCF CDM business. }\end{array}$ & $\begin{array}{l}\text { Failed to analyze the matrix of the } \\
\text { detailed LULUCF changes and was } \\
\text { restricted to an analysis of the profile of } \\
\text { national greenhouse gas inventory. }\end{array}$ \\
\hline & $\begin{array}{l}\text { Achard et al. } \\
(2008)\end{array}$ & $\begin{array}{l}\text { Examined the IPCC guidelines regarding } \\
\text { remote sensing, reviewed cases of } \\
\text { utilizing remote sensing technology for the } \\
\text { construction of a greenhouse gas inventory, } \\
\text { and then proposed a technical methodology } \\
\text { for establishing the LULUCF inventory. }\end{array}$ & $\begin{array}{l}\text { The reviewed technologies were not } \\
\text { applied and remained theoretical. }\end{array}$ \\
\hline \multirow{2}{*}{ Korea } & Choi (2016) & $\begin{array}{l}\text { Surveyed national statistics related to } \\
\text { LULUCF and built a land-use change } \\
\text { matrix on case study lands by using spatial } \\
\text { imagery information. }\end{array}$ & $\begin{array}{l}\text { Used spatial image information to } \\
\text { establish a LULUCF change matrix, } \\
\text { but only for three cities, not the national } \\
\text { level, was analyzed in the case studies, so } \\
\text { the results are insufficient for utilization } \\
\text { in developing the NIR. }\end{array}$ \\
\hline & Yu et al. (2015) & $\begin{array}{l}\text { Traced the degree of changes in the } \\
\text { LULUCF sector by using satellite images } \\
\text { and other spatial information in the } \\
\text { Gyeonggi-do region and then suggested } \\
\text { a detailed statistical construction } \\
\text { methodology for the future. }\end{array}$ & $\begin{array}{c}\text { The scope of analysis was not nationwide } \\
\text { and has limitations in that the degree } \\
\text { of change was analyzed by developing } \\
\text { land use change matrix in } 2000 \text { and } 2009 \\
\text { only. }\end{array}$ \\
\hline Our study & & \multicolumn{2}{|c|}{$\begin{array}{l}\text { Differentiated in that it analyzes the inventory change matrix in the LULUCF sector } \\
\text { nationwide in accordance with the IPCC guidelines and then proposed a methodology } \\
\text { of national greenhouse gas inventory construction in the future. }\end{array}$} \\
\hline
\end{tabular}

First, Landsat TM satellite images with a $30 \mathrm{~m}$ definition were used to examine land-use changes throughout Korea. Coordinate transformation was carried out using the Korean coordinate system, and the geometric correction was assessed by referring to the digital maps. Then, the image of multiple strips was mosaicked into one file to perform color correction, and the whole color tone was unified. An unsupervised classification was performed using ERDAS IMAGINE 2014, and then a supervised classification was performed using unsupervised classification results.

Classification items consisted of six LULUCF categories (forest, cropland, grassland, wetland, settlement, and land used for other purposes) in accordance with IPCC guidelines. ${ }^{(6,13)}$ The training data for each item was selected and the results were confirmed repeatedly to obtain the best results. The accuracy assessment was performed by using the optimal classification results, and the KLIS zoning map was used for reference (Fig. 1).

Finally, overlapping areas and the same land areas in two different results were calculated using ArcMap 10.1 to develop a land-use change matrix over the previous 20-year period. Raster data resulting from a final classification over the last two years was converted into vector data, and then the results of the classification of the six land-use categories from 1987 were clipped to calculate the land area for the land-use categories in 1987. 


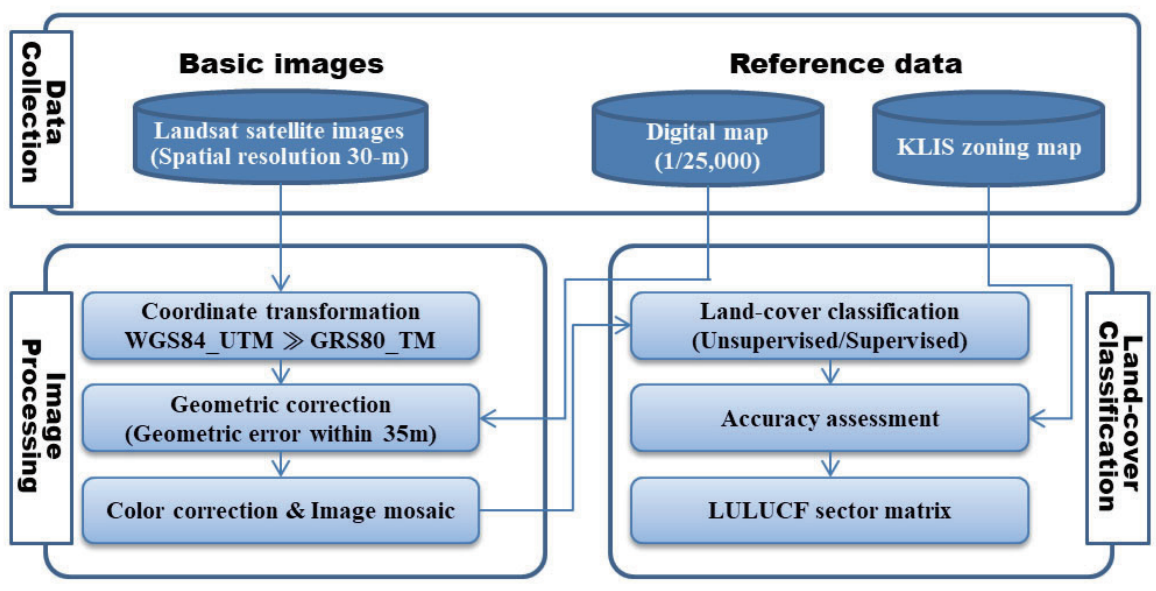

Fig. 1. (Color online) Framework of analysis.

\subsection{Analysis of changes in land use}

The changes in Korea's land use from 1987 to 2007 are reported as follows. The land category conversion rate was highest for settlement. The area of the 1987 settlement that was also the 2007 settlement was $1486.2 \mathrm{~km}^{2}$, which accounts for $71.7 \%$ of the total area in 2007 . New settlement areas in 2007 converted from forest, cropland, grassland, wetland and other land types were $1086.2,2811.6,363.2,59.2$, and $446.7 \mathrm{~km}^{2}$, respectively (Table 4). The total area of settlement increased by $301 \%$ from $2076.6 \mathrm{~km}^{2}$ in 1987 to $6253.1 \mathrm{~km}^{2}$ in 2007 . The areas of settlement converted from cropland and forest were 2811.6 and $1086.2 \mathrm{~km}^{2}$, respectively, making up most of the total, followed by grassland whose proportion decreased by one-third from $3416.8 \mathrm{~km}^{2}$ in 1987 to $2288.8 \mathrm{~km}^{2}$ in 2007 . Next, the total area of forest decreased by approximately $8 \%$ from $67226.4 \mathrm{~km}^{2}$ in 1987 to $61759.8 \mathrm{~km}^{2}$ in 2007 . The remaining land area of preserved forest in 2007 was $58.9 \%$, and approximately $41 \%$ of forested land from 1987 was converted to another land-use category.

In short, a large part of land categorized as cropland and forest in 1987 was converted into settlement, indicating urbanization. The areas of grassland and wetland converted into other categories were statistically insignificant. By region, most of the conversion of other land areas into settlement occurred in the capital area including Seoul, Gyeonggi-do, and Incheon.

The results also indicate substantial conversion into settlement in large cities outside of the capital area owing to urbanization in those regions (Fig. 2). The majority of the cases of landuse conversion to settlement was from cropland and forest, in line with large-scale settlement development in new towns and the development of industrial complexes.

\subsection{Implications}

To prepare statistics for the LULUCF sector in the national greenhouse gas inventory, reference data such as Landsat satellite images, KLIS, and digital topographic maps were used 
Table 4

Matrix of land-use changes in Korea (1987-2007).

\begin{tabular}{|c|c|c|c|c|c|c|c|c|}
\hline & \multicolumn{7}{|c|}{2007} \\
\hline & & Settlement & Forest & Cropland & Grassland & Wetland & Other land & Total \\
\hline \multirow{7}{*}{1987} & Settlement & $\begin{array}{r}1486.2 \\
\end{array}$ & $\begin{array}{r}59.1 \\
(28)\end{array}$ & $\begin{array}{l}289.4 \\
(139)\end{array}$ & $\begin{array}{l}50.0 \\
(24)\end{array}$ & $\begin{array}{l}35.7 \\
(17)\end{array}$ & 156.2 & 2076.6 \\
\hline & Forest & 1086.2 & $\begin{array}{r}57770.7 \\
(859)\end{array}$ & $\begin{array}{r}6113.2 \\
(92)\end{array}$ & $\begin{array}{r}1230.9 \\
(18)\end{array}$ & 143.8 & 881.6 & 67226.4 \\
\hline & Cropland & $\begin{array}{r}2811.6 \\
(11.8)\end{array}$ & $\begin{array}{r}2630.9 \\
(11.1)\end{array}$ & $\begin{array}{r}16543.8 \\
(69.6)\end{array}$ & $\begin{array}{l}521.7 \\
(2.2)\end{array}$ & $\begin{array}{r}299.0 \\
(1.3)\end{array}$ & $\begin{array}{r}962.5 \\
(4.0)\end{array}$ & 23769.5 \\
\hline & Grassland & $\begin{array}{l}363.2 \\
(10.6)\end{array}$ & $\begin{array}{r}1095.5 \\
(32.1)\end{array}$ & $\begin{array}{r}1387.6 \\
(40.6)\end{array}$ & $\begin{array}{l}377.7 \\
(11.1)\end{array}$ & $\begin{array}{l}41.3 \\
(1.2)\end{array}$ & $\begin{array}{r}151.5 \\
(4.4)\end{array}$ & 3416.8 \\
\hline & Wetland & $\begin{array}{l}59.2 \\
(8.9)\end{array}$ & $\begin{array}{l}30.0 \\
(4.5)\end{array}$ & $\begin{array}{l}272.9 \\
(41.0)\end{array}$ & $\begin{array}{l}23.1 \\
(3.5)\end{array}$ & $\begin{array}{l}120.1 \\
(18.0)\end{array}$ & $\begin{array}{l}160.9 \\
(24.1)\end{array}$ & 666.2 \\
\hline & $\begin{array}{l}\text { Other land } \\
\text { types }\end{array}$ & $\begin{array}{l}446.7 \\
(14.6)\end{array}$ & $\begin{array}{r}173.6 \\
(5.7)\end{array}$ & $\begin{array}{l}496.2 \\
(16.3)\end{array}$ & $\begin{array}{l}85.4 \\
(2.8)\end{array}$ & $\begin{array}{r}270.7 \\
(8.9)\end{array}$ & $\begin{array}{r}1576.6 \\
(51.7)\end{array}$ & 3049.2 \\
\hline & Total & 6253.1 & 61759.8 & 25103.1 & 2288.8 & 910.6 & 3889.3 & \\
\hline
\end{tabular}

Unit: $\mathrm{km}^{2},(\%)$

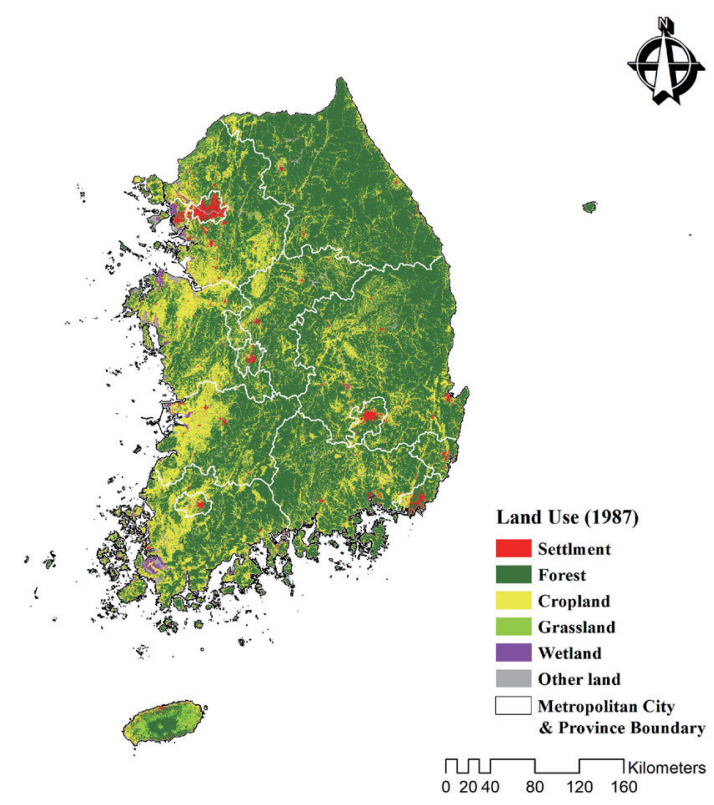

(a)

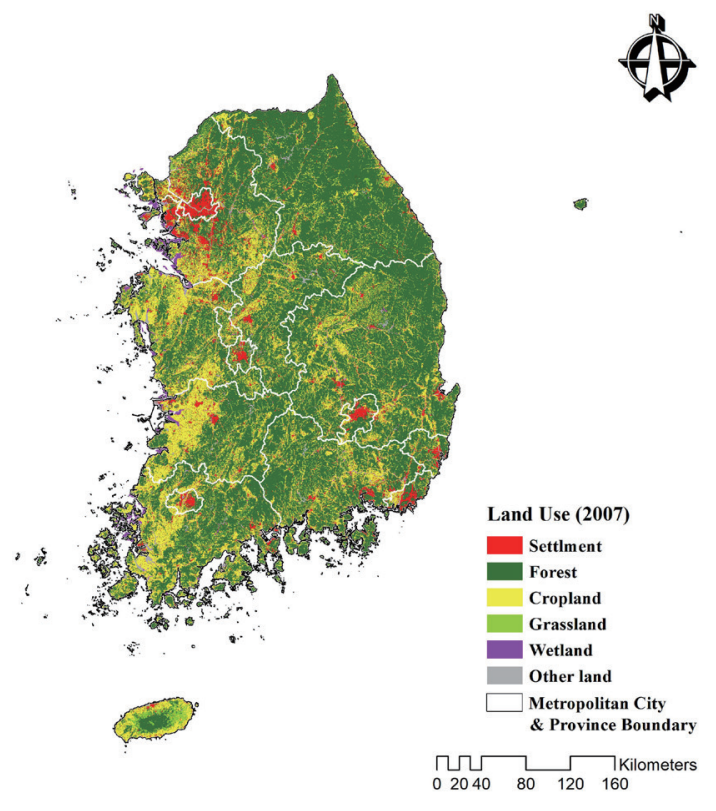

(b)

Fig. 2. (Color online) Korea's land use in (a) 1987 and (b) 2007.

to analyze land-use changes in Korea for the 20-year period between 1987-2007. The following implications were understood from the results of this case study on land-use changes in Korea.

First, a clear classification system for each category in the LULUCF sector needs to be established. In the analysis, the six categories of land use suggested by the IPCC were reclassified concerning the KLIS land-use zoning maps. However, land-use categories such as golf fields and cemeteries could not be defined as carbon sinks, so they were included in 
this analysis as other land types within the category of grasslands. Therefore, it is necessary to redefine some of the subcategories of land use to ensure consistency with the land-use categories defined by the IPCC, to develop an LULUCF inventory.

Second, efforts to increase the accuracy in the use of diverse reference data from satellite images are necessary. This case study analysis was conducted by referring to digital topographic, land cover, and KLIS maps using the current land-use status, based on satellite images. However, to conduct a more detailed analysis of the data for land-use conversion in each LULUCF category, further study of the diverse methodologies for establishing the data in connection with other high-definition satellite images and spatial information systems will be essential.

Third, spatial big data technologies for processing large high-definition satellite images and diverse spatial information must be applied to this process. High-definition satellite image data and diverse nationwide spatial information used as references are substantial in size and also contain a significant volume of information about land-use attributes. ${ }^{(14)}$ The data size of a Landsat TM satellite image used for analysis in this study includes 12 map indexes equivalent to a total of $3.9 \mathrm{~GB}$. Also, the number of records processed to calculate the land-use change area was 1.5 million. Thus, to process this scale of spatial data quickly and accurately, technologies for the storage, management, and analysis of these data using Spatial Hadoop must be developed.

\section{Method of Constructing LULUCF Inventory Statistics}

\subsection{Basic direction}

For the systematic construction of the statistics for the national greenhouse gas inventory of the LULUCF sector; first, accurate information regarding the area of land attributed to each of the six land categories is required; statistics on land conversion other land-use categories must be determined, and data must be constructed. Also, greenhouse gas emission statistics for LULUCF are prepared by calculating the area of land remaining in each category and the area of land converted from other categories. However, the greenhouse gas statistics for each land-use category have not even been constructed yet in Korea owing to the lack of information about the land-use area for each category and the area of land converted from other landuse categories. ${ }^{(15,16)}$ Therefore, statistics on changes to land-use data must be prepared using the data collected for the National Spatial Data System. Currently, government agencies and departments establish LULUCF-related statistics separately, but they fail to monitor the total area of land in each land-use category or information about the conversion from other land-use categories. To solve these problems, the land area in each LULUCF category is estimated using data from the National Spatial Information and consistency is checked using the total land area (Fig. 3).

Korea has yet to fully establish the data required to track changes in land use and estimate the exact land area or land-use category. Accordingly, spatial information data for each of the LULUCF categories must be established by using satellite images. This is the most effective 


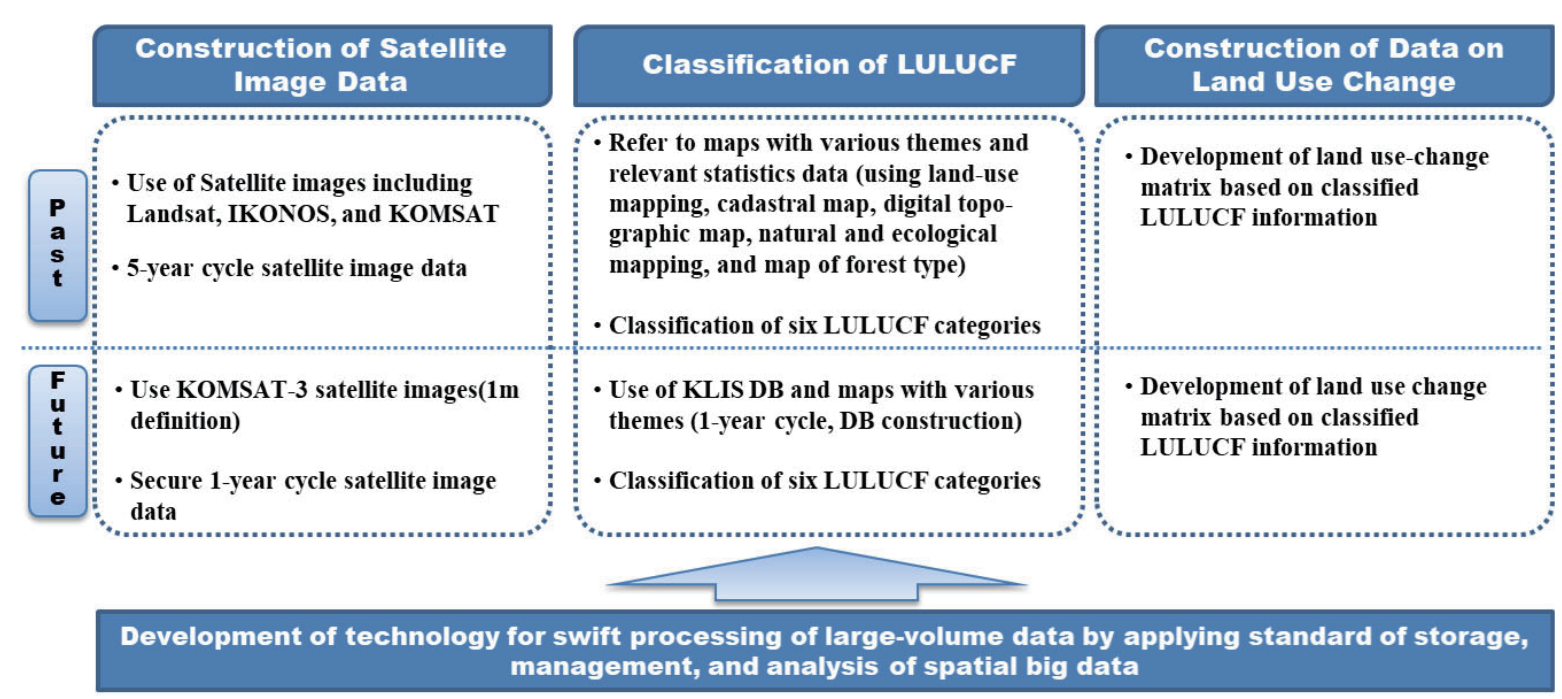

Fig. 3. (Color online) Method of constructing LULUCF statistics.

way of extracting data on land-use changes since previous studies, as recommended by the IPCC. Annex I lists the state parties using statistical methods to construct statistics connected with diverse spatial information including high-definition satellite images, for the construction of statistics for the LULUCF sector to track land-use changes over the past two decades. Therefore, Korea also needs to construct data to process land-use changes in the LULUCF sector by using remote sensing technologies with satellite images, in connection with the diverse range of spatial information that has been collected to date. Along with establishing these statistics, efforts to apply the big data storage, management, and analysis technologies to processing large volumes of spatial data with multiple attributes are necessary.

\subsection{Method of extracting spatial information by using satellite images}

After extracting LULUCF land-use classification categories from satellite images, spatial information regarding each of the six LULUCF categories is also extracted. Along with satellite images, different thematic maps and statistics are referred to for each land-use attribute to extract boundaries. The references for attribute information about land classifications include land-use maps, cadastral maps, digital topographic maps, land zoning maps, city planning maps produced by the Ministry of Land and Transportation, ecological zone maps produced by the Ministry of Environment, and forest maps from the Korea Forest Service. Also, satellite images that can be used at the moment could be secured to extract boundaries between different landuse categories.

Such land-use classifications can be determined for forest, cropland, grassland, wetland, settlement, and other land types, which are equivalent to the LULUCF categories suggested by the IPCC. For example, the land thickly covered with vegetation is extracted as forest in the 
form of satellite infrared images. The land covered with vegetation for the use of people, such as cultivated land, and orchards, as well as bare soil can be classified or extracted as cropland. The land lightly covered with vegetation is extracted as grassland, and submerged land is extracted as wetland. The land identified as being covered with concrete from satellite images and is $62500 \mathrm{~m}^{2}$ or larger in area is extracted as settlement. Then, green belts within residential land are extracted using infrared images and classified as other land types. ${ }^{(17-20)}$

The principle for extracting the spatial information about each of the LULUCF categories is to use satellite images but refer to thematic maps and other relevant statistical data. ${ }^{(17)}$ The use of satellite images requires geometric and orthometric correction for the interpretation and digitalization of the images. ${ }^{(18,21)}$ Maps with different themes such as land-use, cadastral, digital, ecological zoning, topographic, and forest maps, as well as land-use category statistics, can be used for geometric and orthometric correction.

\subsection{Method of preparing statistics on land-use changes}

First, as spatial data regarding past changes in land use, with which land-use changes over the past 20 years can be tracked and land areas for each category can be estimated, has not been fully developed yet. Satellite images must be used to establish data on past changes in land use. Satellite images currently available for preparing statistics on land-use changes in the past in Korea include images obtained from LANDSAT (five-year cycle) from 1993 to 2004, and KOMPSAT from 2003 to present (28-day cycle), as well as images obtained from IKONOS. However, to track changes in each LULUCF category, including residential land, 1-m-level high-definition satellite images must be used. Statistics of land-use changes should be prepared by tracking past changes in land use utilizing LANDSAT, KOMPSAT, and IKONOS satellite images and correcting them by referring to different thematic maps to obtain relevant statistics. Also, the data of land-use changes must be constructed by using accessible satellite images and diverse spatial information between 2000 and the present. Then, land use information at the point for statistical construction must be collected to prepare the statistics. Finally, statistical data on land-use changes for each year must be prepared to interpolate the results.

Data for land-use changes in the future is necessary for statistical construction at the level of AFOLU, which can be established using satellite image data with higher precision levels. ${ }^{(6)}$ KOMPSAT-3 (1-m-level resolution) satellite images can be used to obtain data of land-use changes since 2012, while the database of different thematic maps and statistical data from the KLIS can be used to consistently measure the areas of land-use categories that have changed. Also, data on land-use changes for each LULUCF category nationwide for each year since 2012 must be constructed using KOMSAT-3 satellite images managed by the Korea Aerospace Research Institute. Then, the accuracy of the data must be improved by carrying out corrections based on the data from the KLIS and different thematic maps from the Ministry of Land and Transportation and the Ministry of Environment.

The time frame for the construction of different sections of the KLIS database is different, so it is not possible to construct a time-series database. Therefore, it is necessary to plan the timing of the construction of time-series data, in order to prepare data about future land-use 
changes. Also, the time-series database collected and added to every year from the KLIS data must be used as data to correct the database of land-use changes. For this purpose, images and relevant data with higher precision levels must be used to track the locations of the land-use category conversions necessary to construct statistics at the AFOLU level in the future.

\section{Conclusions}

Since 2011, Korea has been implementing a range of diverse policies to reduce greenhouse gas emissions after setting a 30\% reduction target compared with BAU for 2020. To support this policy, statistics from each greenhouse gas inventory sector must be established, and appropriate reduction measures should be established, in accordance with these data. To date, the systematic construction of statistics has already been conducted for the energy, industrial processing, agriculture, and waste sectors. However, as of 2017, statistics for the LULUCF sector are still lacking. Accordingly, this study was conducted to devise a method for the preparation of LULUCF statistics. The results of a review of the theoretical background and previous work on this topic have shown that statistics for the area of land in each LULUCF category and the areas of land-use categories that have been converted to different land-use categories must be systematically constructed in accordance with IPCC guidelines. However, no such land-use category conversion statistics currently exists in Korea. To propose a method for resolving this problem, we analyzed changes in land use for LULUCF categories across Korea using satellite images, digital topographic maps, land cover maps, and data from the KLIS accumulated over a 20-year period between 1987 and 2007. Also, a change matrix for the six land-use categories suggested by the IPCC guidelines was developed to establish accumulated data changes for land use over the same period. The results of this analysis yielded meaningful conclusions about the classification of each LULUCF category, the improvement of statistical accuracy when using satellite images, and the necessity of developing a method for the application of spatial big data technology. On the basis of the results or the review of the theoretical background and previous case study analyses, we propose a methodology for the systematic construction of statistics for the national greenhouse gas inventory for the LULUCF sector in the future. To ensure that the LULUCF statistics are recognized by the IPCC, landuse category change data were systematically constructed for a 20 -year period. We propose the method of constructing a land-use change matrix from satellite images and diverse spatial information systems.

To reduce greenhouse gas emissions in line with the Paris Agreement, the systematic construction of greenhouse gas emission statistics for each sector is essential. For this purpose, diverse policies and action plans for each sector must be developed on the basis of accurate greenhouse gas statistics. The methodology proposed in this study will help to track changes in the LULUCF sector at the national level and construct relevant statistics, thereby leading to a practical reduction in greenhouse gas emission. 


\section{Acknowledgments}

This research, 'Geospatial Big Data Management, Analysis and Service Platform Technology Development', was supported by Korea's Ministry of Land, Infrastructure and Transport (MOLIT), under the national spatial information research program supervised by the Korea Agency for Infrastructure Technology Advancement (KAIA) (19NSIP-B081011-06).

\section{References}

1 Greenhouse Gas Inventory \& Research Center of Korea: 2016 National Greenhouse Gas Inventory Report of Korea (GIR, Seoul, Korea, 2016).

2 E. J. Choi, J. H. Lee, H. C. Jeong, S. H. Kim, J. S. Lim, D. K. Lee, and T. K. Oh: Korean J. Agric. Sci. 44 (2017) 4. https://doi.org/10.7744/kjoas.20170055

3 J. M. Park, J. S. Yim, and J. S. Lee: J. For. Environ. Sci. 33 (2017) 4. https://www.earticle.net/Article/A314118

4 J. T. Houghton, L. G. Meira Filho, B. Lim, K. Treaton, I. Mamaty, Y. Bonduki, D. J. Griggs, and B. A. Callender: Revised 1996 IPCC Guidelines for National Greenhouse Gas Inventories (IPCC, 1996).

5 J. Penman, D. Kruger, I. Galbally, T. Hiraishi, B. Nyenzi, S. Emmanul, L. Buendia, R. Hoppaus, T. Marinsen, J. Meijer, K. Miwa, and K. Tanabe: Good Practice Guideline and Uncertainty Management in National Greenhouse Gas (IPCC, 1996).

6 J. Penman, M. Gytarsky, T. Hiraishi, T. Krug, T, R. Pipatti, L. Buendia, K. Miwa, K. Tanabe, and F. Wagner: Good Practice Guidance for Land Use, Land-Use Change and Forestry (IPCC, 2003).

7 S. Eggleston, L. Buendia, K. Miwa, T. Ngara, and K. Tanabe: 2006 IPCC Guidelines for National Greenhouse Gas Inventories (IPCC, 2006).

8 M. A. Teixeira, M. L. Murrary, and M. G. Carvlho: Ecol. Econ. 60 (2006) 1. https://doi.org/10.1016/ j.ecolecon.2005.12.003

9 D. Aaron and B. Sandra: 2003 International Conference on Topical Forests and Climate Change: Carbon Sequestration and the Clean Development Mechanism (ICTFCC, 2003).

10 F. Achard, G. Grassi, M. Herold, M. Teobaldelli, and D. Mollicone: In Background Paper at the IPCC Expert Meeting (IPCC, 2008).

11 I. H. Choi: Clim. Change Green Growth 11 (GIR, Seoul, 2016).

12 S. C. Yu, J. W. Ahn, and J. A. Ok: J. Korea Spatial Inf. Soc. 23 (2015) 3. https://doi.org/10.12672/ ksis.2015.23.3.067

13 H. Kramer, G. J. Van den Born, J. P. Lesschen, J. Oldengarm, and W. Van den: Land Use and Land Use Change for LULUCF Reporting under the Convention on Climate Exchange and the Kyoto Protocol (Alterra, 2009).

14 M. S. Yang, J. W. Ahn, and D. B. Shin: Spatial Inf. Res. 26 (2018) 175. https://doi.org/10.1007/s41324-0170162-y

15 Y. J. Bae, S. J. Bae, I. H. Seo, K. Seo, J. J. Lee, and G. Y. Kim: J. Korean Soc. Rural Plann. 19 (2013) 125. https://doi.org/10.7851/ksrp.2013.19.4.125

16 G. Y. Kim, G. H. Kim, H. H. Kim, J. D. Shin, J. T. Lee, J. W. Jeong, and S. Y. Hong: Estimate Total Emissions and Removals of Agricultural Greenhouse Gases by IPCC Guidelines on Climate Change Convention (NIAST, Suwon, Korea, 2015)

17 J. Y. Ku, B. S. Kim, and J. J. Park: J. Korea Spatial Inf. Soc. 15 (2007) 1.

18 K. J. Shin, Y. G. Yu, and E. J. Hwang: J. Korean Geoenviron. Soc. 6 (2005) 4.

19 M. Kidane, T. Tolessa, A. Bezie, N. Kessete, and M. Endrias: Spatial Inf. Res. (First Online 15 Nov 2018). https://doi.org/10.1007/s41324-018-0222-y

20 H. T. Do, V. Raghavan, L. X. Truoung, and G. Yonezawa: Spatial Inf. Res. (First Online 06 Feb 2019). https:// doi.org/10.1007/s41324-019-00240-w

21 M. Z. Al-Hamdan, P. Oduor, A. I. Flores, S. M. Kotikot, R. Mugo, J. Ababu, and H. Farah: Int. J. Appl.Earth Observation Geoinformation 62 (2017). https://doi.org/10.1016/j.jag.2017.04.007 


\section{About the Authors}

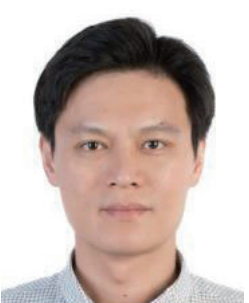

Seon Cheol Yu received his B.S., M.S., and Ph.D. degrees from Anyang University, Korea, in 2003, 2005, and 2011, respectively. From 2011 to 2014, he was an associate research fellow at Korea Research Institute for Human Settlement, Korea. Since 2014, he has been a research professor at Anyang University. His research interests are in urban planning, big data, smart city, and urban regenerations. (katarsis717@gmail.com)

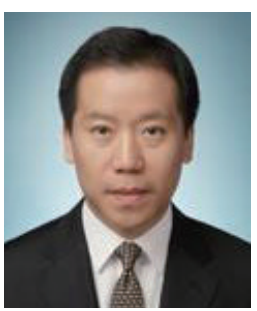

Dong Bin Shin received his B.S., M.S., and Ph.D. degrees from Yonsei University, Korea, in 1987, 1989, and 1999, respectively. From 1995 to 2012, he was a research fellow at Korea Research Institute for Human Settlement, Korea. Since 2012, he has been a professor at Anyang University. His research interests are in spatial data policy, geospatial big data, and smart city services. (dbshin@anyang.ac.kr)

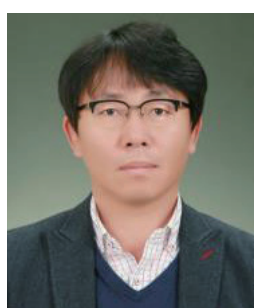

Jong Wook Ahn received his B.S., M.S., and Ph.D. degrees from Anyang University, Korea, in 2000, 2002, and 2007, respectively. From 2007 to 2011, he was an associate research fellow at Korea Research Institute for Human Settlement, Korea. Since 2011, he has been a professor at Anyang University. His research interests are in urban planning, smart city, big data, and spatial information.(ajw0603@anyang.ac.kr) 